\title{
Flea Market Voices on Literacy in Botswana
}

\author{
Arua E. Arua ${ }^{1}$ \\ University of Botswana
}

\begin{abstract}
This paper presents the views of some flea market vendors and clients, especially those whose voices are never heard, on the literacy and education issues that affect Botswana. Although small, the sample of respondents used for this study is representative of the kinds of people that populate flea markets. However, a large percentage of the respondents are male, thus indicating that male voices are dominant even in this setting. The findings of the study, which are similar to those in the literacy literature on Botswana, include the following: children lack interest in reading; parents have not been involved in their children's reading development; and there are inadequate library and other resources to support a reading culture in Botswana. Some respondents advocate direct teaching of reading to their children, procuring reading materials for them and sending them to good private schools as ways of improving their children's reading. Overall, the study shows that there is need to complement the top-down approach with the bottom-up approach, as there are valuable lessons policy makers can glean from canvassing the views of those in non-traditional government structures such as the flea markets.
\end{abstract}

\section{Introduction}

This paper, abstracted from a larger project (Arua, 2011), is motivated by two factors. The first is that flea markets which were hitherto neglected settings (Maisel, 1974; McEnally, 1998; Sherry, 1990) are now the sites in which marketing and a wide range of other issues are increasing being discussed or studied (Chivivi, Moyo \& Mapuwei, 2014, for example). The second is that it is a setting that can be used to educate marginalized Batswana and to enlighten them on "the benefits and value of continued literacy education for all" (Brown, Epners, \& Gauvin, n.d., p. 1). In order to understand how literacy can function in a flea market setting, it was necessary to solicit the views of flea market participants whose voices are not usually represented in the discussion of literacy issues in Botswana. The main objective of this paper, therefore, is to report the views of such participants, especially their recommendations on aspects of literacy that the government of Botswana should focus on. The paper thus answers the question: what do the flea market clientele in Botswana believe are the literacy issues that the government of Botswana should focus on in the delivery of literacy or education for all?

\section{Botswana's flea markets}

Botswana's flea markets conform to the definition of open-air markets that sell "second-hand goods at low prices" (Waite, 2007, p. 395). The markets are located in open malls (the Main Mall and the BBS Mall, for example) alongside big name stores such as SPAR, PEP and Pick n Pay. The flea markets that attract a diverse clientele are now a permanent feature of Botswana's commercial landscape. They operate on a daily basis, but Saturdays attract the greatest number of vendors and diverse groups of people with wide socio-economic backgrounds. The vendors found in the flea markets are those who are usually not able to afford the money to rent expensive

\footnotetext{
${ }^{1}$ Arua E. Arua is a professor of Language and Linguistics at the University of Botswana, Gaborone. A member of the Reading Association of Botswana and the International Reading Association, his areas of specialization are Applied Linguistics, Literacy, Language and Gender and Stylistics. Email: aruaae@mopipi.ub.bw
} 
shops in the malls. Nevertheless, those who want to set up stalls have to pay to the City Councils, in the towns where they wish to set up their stalls, token amounts of money for different space sizes. There are small, medium, and large-scale ventures competing with big name stores in Botswana's flea markets.

\section{Flea market literacy}

Very limited research has been done on flea markets and none at all, as far as I am aware, on flea market literacy. Sherry (1990) puts it this way: "Academic research into flea markets has yielded a rather small and circumscribed literature of discontinuous quality" (p. 14). McEnally (1998) agrees that the lack of academic literature pertaining to flea markets results in the provision of general flea market information. One of the few researchers on the subject, Maisel (1974), regards flea markets as popular sites of research action which Tamukamoyo (2009) says are mainly sites of economic production and exchange and of diverse social relations. The popularity of flea markets, which are a worldwide phenomenon as sites of economic production and exchange is seen in what Parker (2011) describes as "the flea marketization of New York" (p. 1). Apparently, the flea markets are ubiquitous, as they appear in every part of the city. Indeed, Sherry (1990) describes the flea market as a complex socioeconomic institution to which a great deal of attention should be paid.

McEnally's (1998) exploratory analysis of flea market shoppers supports the view that everybody attends flea markets, and that "shoppers at general flea markets are not significantly different from the general population" (p. 10). In other words, diverse groups of people, celebrities included, consider them as places of interest both for the economic and social activities that take place in them (Parker, 2011). That is why Sherry (1990) rightly suggests that patrons of flea markets should be targeted for future research on account of the fact that they reflect the structure of society. This finding is important for this study because, although it targets those whose literacy needs are not met through traditional government structures, and those whose literacy views are not represented in Botswana, it shows that the flea market cannot be viewed as inferior to other societal structures. This is why Sherry (1990) describes it in economic terms as "an alternative marketing system that complements and articulates with more commonly understood marketing systems" (p. 13).

The foregoing characterization of the flea market shows it as an entity that should be intensely studied. This paper is thus necessary in that it highlights the need to research how flea markets can be used as sites for supporting and promoting economic and other types of research, including that on literacy. The paper therefore increases the very scant flea market literacy literature, which future researchers can consult for their studies.

\section{Methodology}

The study design is that of a survey. The survey data were collected from three flea markets at the Main Mall and BBS Mall in Gaborone, and the Lobatse City Center using a questionnaire adapted from an International Reading Association survey which sought to ascertain the acceptability of its new philosophical foundation: "We teach the world to read". A copy of the questionnaire is attached as an appendix.

A simple but non-conventional random sampling procedure was used in eliciting responses from a small sample of 28 respondents. The respondents were a very small percentage of a large and indeterminate study population that visited the project tents to browse the literacy materials on display, ask questions about the literacy activities and objectives of the project, and air their views about literacy and education in Botswana. It is to those who wished to air their views or who were persuaded to do so that the questionnaire on literacy in Botswana was administered. Not all 
of those who had something to say wished to fill out a questionnaire or had the time to do so in the fast-paced environment of the flea markets where time is usually at a premium and everybody is in a hurry to achieve their economic goals for the day. The sampling procedure was therefore random in the sense that it was impossible to predict those who would be willing to participate in the data collection exercise. Because of this, it is difficult to estimate the population from which the sample was selected.

Although the sample size is small, it is certainly representative, as it confirms McEnally's (1998) view that everybody attends flea markets and that there are no demographic differences in them. The diversity of the people who filled out the questionnaire during the project period at Botswana's flea markets can be seen in terms of their professions: an electrician, five teachers, two IT technicians, a nurse, a marketing manager, a flea market vendor, a student, an attorney, an auditor, three project/business managers, a self-employed person, a jeweler, a librarian, a retired civil servant, an engineer, an unemployed person, a medical practitioner and a researcher. Three persons did not respond to this questionnaire item.

In terms of educational qualifications, the diversity is also apparent: two (7.1\%) were students, fifteen $(53.6 \%)$ had non-degree qualifications (Botswana General Certificate of Secondary Education, postsecondary certificates such as primary teachers' certificates and diplomas of various kinds-Human Resources and Purchasing and Supply) and eleven (39.3\%) were degree holders. It is interesting to note that participants who were not proficient in English, fiercely rebuffed attempts to help them with the questionnaire. English, the official language of Botswana, is prestigious, and some of the participants wanted to show that they could speak or write it well. It was not surprising, therefore, that some participants wanted to prove their proficiency in the language by refusing the help proffered by the project assistants.

There was a clear gender disparity in favor of males regarding the 28 participants who filled out the questionnaire. A total of 21 respondents (75\%) were male while $7(25 \%)$ were female. This disparity, which is difficult to explain, implies that the views expressed in this study are mainly those of males. The findings of the study are presented and discussed using a simple descriptive statistical procedure. Accordingly, percentile scores have been used where they are deemed to be necessary. The findings are discussed below.

\section{Discussion of Findings}

There are two sets of findings. The first relates to issues that the respondents believe should occupy the attention of education authorities in Botswana. The second deals with the roles of parents/teachers in helping their children, wards or pupils acquire literacy in and outside of school.

\section{Main Literacy Issues in Botswana}

The main concerns of $96 \%$ (27 out of 28 ) of the respondents are not only wide ranging but also relate to the core educational issues and themes that are in the literature on literacy as they relate to Botswana. Table 1 contains some of the issues the respondents raised:

Table 1

Main Literary Issues in Botswana

\begin{tabular}{llll}
\hline No & Issues & $\mathrm{N}$ & $\%$ \\
\hline 1 & Lack of interest in reading (to acquire knowledge) & 8 & 22.9 \\
2 & Lack of support from uneducated parents for their children & 1 & 2.9 \\
3 & In ability to motivate their children to read & 3 & 8.5 \\
4 & Shortage/lack of reading facilities/resources & 6 & 17.1 \\
5 & No reading culture & 2 & 5.7
\end{tabular}




\begin{tabular}{llll}
6 & Unemployment and poverty & 2 & 5.7 \\
7 & Lack of time for children to read in school & 1 & 2.9 \\
8 & Parents and teachers not taking education seriously in rural areas & 3 & 8.5 \\
9 & Parents do not buy reading materials for their children & 1 & 2.9 \\
10 & Kids are more into TV/internet/movies & 3 & 8.5 \\
11 & Lack of awareness of reading/lack of outreach programs & 2 & 5.7 \\
12 & No attempt to improve public schools by government & 1 & 2.9 \\
13 & Language barrier & 1 & 2.9 \\
& Total & 35 & 100 \\
\hline
\end{tabular}

Table 1 contains the number of issues raised rather than those who raised them. Indeed, some respondents raised more than one issue and some did not mention any.

Children's Lack of Interest or Motivation in Reading

As Table 1 shows, $65 \%$ of the comments (see items 1, 3, 4, 5, 6, 9 and 10) relate to lack of interest in reading and other reading-related issues. According to some of the respondents, children and adolescents do not have the zeal or hunger (interest, passion or motivation) to read. Further, according to respondents, the children do not wish to acquire knowledge through reading; rather, they want to be spoon-fed with knowledge. The lack of interest in reading has been related to lack of a reading culture (see Arua \& Arua, 2011, for a summary of the research on reading culture in Botswana). The respondents' views seem to support similar views of educated Batswana who have the impression that Botswana lacks a reading culture (Baputaki, 2006; Hosia, 2007; Seboni \& Swartland, 2009). The respondents proffer a number of solutions to the children's apparent lack of interest in reading. Some are of the view that children and students should:

- be made aware of the importance of reading for themselves;

- read school books and (sic) anything to do with education;

- $\quad$ read in their spare time; and

- be encouraged to read and practice constantly, and in a fun way...

These echo Arua and Arua (2011) who have argued for a redefinition of reading culture in Botswana to include leisure reading and reading that is done for utilitarian purposes. With regard to the availability of time to read, one of the respondents, a student, said that the double shift educational system (in which there are two schools-one in morning and one in afternoon) introduced recently in Botswana has reduced the time available for reading. Though it has been argued that the time available for junior students for leisure reading is inadequate (Arua, 2014), it is unclear how the double shift system has affected the students' reading time.

Inadequate Parental and Teacher Involvement in Reading

Some of the respondents claim that parents and teachers do not sufficiently support their children's reading and education (30\% of the entries in Table 1 - see items 2, 3, 7 and 8 ). This is so because some teachers are not taking education seriously and some parents:

- $\quad$ are not well educated, especially in the rural areas

- lack information on reading

- do not buy books and magazines for their children

Mathangwane and Arua (2006) also observed that parents in rural areas are not able to help their children because of their poor educational backgrounds. The view that many parents in the rural areas, especially in the northwest of Botswana, as one respondent asserts, neither take education seriously nor bother about 
it must be related to the factor of lack of education. Lack of information on reading or awareness of issues related to reading was a major factor for all the respondents who visited the project sites from where the data for this study were collected. Commyeras and Mazile (2011) show that teachers in primary schools do not read and are therefore unable to model reading for their students. A similar result was obtained by Arua (2014) in respect of four junior secondary schools. Finally, most parents do not support their children's literacy practices because they do not buy books for their children to read. This limits the ability of the children to develop a passion for reading. Arua and Arua (2011) contradict this view. They found that many parents buy reading materials for their children who are in junior secondary schools although women are better at it than men are. This issue of the procurement of books will be further discussed later in this paper.

\section{Unemployment and Poverty}

Some respondents indicate that unemployment and poverty may account for why parents do not adequately attend to their children's literacy needs (30\% - see items 2, 4, 6, 8 and 9$)$. More importantly, the respondents believe that parents should be taught the importance of education (again one respondent was particular about the Northwest). They also say that the shortage of reading facilities should be reversed.

\section{Inadequate Libraries and the Shortage of Resources}

A number of respondents were particular about the inadequacy of libraries and the shortage of resources in them (20\% - see items 4 and 9). There are many studies such as Ntlameleng (1982) and Jongman (1999) that have also noted the inadequacy of the libraries in Botswana. The respondents also indicated that the libraries are few or out of reach, and that, as a result, students turn to or prefer to do sports. Inaccessibility of libraries has also been noted worldwide as a problem (Kamberelis \& Albert, 2007). One primary school teacher insists that libraries should not only be available, they should be accessible even on weekends. Regarding shortage of resources, the respondents' claim is that Botswana libraries do not contain a wide range of reading materials, a point that Olaofe (2003) has noted for the Nigerian context. In other words, there is no access to good reading materials (i.e. culturally relevant materials and materials adequate for different grade levels). Finally, some respondents say that public schools and their libraries should be improved by adding IT resources to them. This would have the overall effect of pulling or attracting children to the libraries and to the vast information available in them. Arua et al. (2005) examined junior school libraries across Botswana and arrived at a similar conclusion; that they would become more attractive and more exciting if computers, for example, were part of the resources available in them.

\section{Educating the Community on the Importance of Reading}

Some responses show that educating the community on the importance of reading is a concern $(22.7 \%$-see items 3, 8 and 11$)$. One of the major points that the respondents highlighted is that there are no community resource centers where information regarding reading can be accessed. This suggests that respondents are obviously not aware of the Village Reading Rooms initiative that Hanemann (2005) has described at length. This lack of awareness supports their call for educating Batswana about the resources available to them in their communities. It also supports the view that the libraries in Botswana and NGOs such as the Reading Association of Botswana have not done much to promote reading in various communities in Botswana. The respondents then stress the need for libraries and the Reading Association of Botswana to engage in more outreach activities/programs that would include educating people even on the relationship between modern technology and reading. A related point made by the respondents is that children have no guidance and motivation to read at home. These factors have been highlighted elsewhere in this paper.

\section{Issues Related to Audio-visual Technology}

The use of technology in reading and in education, mentioned in Table 1, was more elaborately addressed as Table 2 shows. 
Table 2

Technology in reading and education in Botswana

\begin{tabular}{llll}
\hline No & Issues & $\mathrm{N}$ & $\%$ \\
\hline & Positive role & & \\
1 & Vital role in improving literacy & 11 & 34.3 \\
2 & Kids have to read info on TV/computer in order to use it & 5 & 15.7 \\
3 & Learn new words/pronunciation while watching TV & 3 & 9.4 \\
4 & Aids research & 1 & 3.1 \\
& Total & 20 & 62.5 \\
\hline \multirow{2}{*}{5} & Negative role & & \\
6 & Hinders progress & 3 & 9.4 \\
7 & Too much time spent on watching/using technology & 6 & 18.8 \\
8 & Few PCs in schools & 2 & 6.2 \\
& Relegates reading as same available on TV/radio & 1 & 3.1 \\
& Total & 12 & 37.5 \\
& Overall total & 32 & 100 \\
\hline
\end{tabular}

The issue related to audio-visual technology elicited both positive and negative views from the respondents. About $37.5 \%$ of the entries in the table are to the effect that technology has a negative impact on the lives of the children; it hinders their educational progress. However, the main grouse of those (50\% of them) who cite its negative impact is that children spend too much time on TV and that this distracts them from performing worthwhile reading related tasks. One of the respondents indicated that it relegates reading, as the same information in print materials is available on TV and radio. In other words, the number of students reading print materials is low because the TV and the Internet are more interesting.

The majority of entries in Table $2(62.5 \%)$ is to the effect that audio-visual technology has a positive influence on the children and should be part of the modern day classroom:

- Some issues in education are very hard to grasp... through just reading without seeing demonstrations through videos

- Encourage children to watch [talk shows on TV] and join talk shows in their schools and debating clubs.

- Kids have to read info on the computer in order to use it

The view that technology has a beneficial effect on reading is now an acknowledged fact in reading research. In the "Reading, Writing and Technology" brochure, the International Reading Association (2008) provides a position statement that indicates how parents and teachers can maximize the benefits of "new media" and "new literacies" of which various technologies are a part. It would be necessary to educate parents and teachers about how to exploit these new media and discourage their children from using them inappropriately.

Parents' Role in Reading and Literacy

In the previous section, the inadequate role of parents in the reading lives of their children was highlighted. In this section, 23 (or $82 \%$ ) of the respondents comment on the role that parents and guardians actually play or should play in their children's reading endeavor. As Oyegoke (2012) notes, some parents and teachers conflate the notions of "reading" and "studying". This implies that they see their role as that of enabling their children not only to become literate but also to become well-educated. In order to play this role effectively, they perform the three related actions now discussed below. 


\section{Direct Teaching of Reading}

Approximately half of the respondents (12 of the 23) identified above indicated that they were directly involved in teaching their children how to read:

- I taught them at home.

- I read with them.

- I encouraged them to read anything readable.

- I told them to study (I encouraged them to get involved in study groups).

- I took them to visit the libraries.

- I encouraged them to read newspapers and magazines.

- I took part in their studies.

One respondent who has a child with a reading problem attempted to help him/her as follows:

- I had to make words into pieces. To match them until we make a word together. It is uncertain that this self-help procedure was efficacious; it would have been better to refer the child to a center for those who have reading disabilities or challenges.

It is commendable that parents do not want to leave the literacy lives of their children to chance and, thus, are directly or intimately involved in what their children read and study. Such involvement presupposes, erroneously, in my view, that many parents understand what to do with reading challenged children. In other words, referral to appropriate centers and availability of wellstocked reading centers would go a long way in educating parents and teachers about how to help their "normal" or reading challenged children. In recognition of the roles that parents can play in the reading development of their children, some of the International Reading Association brochures should be made available to parents who are literate in English. The brochures can also be translated into Setswana, the national language, as Arua (2011) did, for those parents who are literate in it.

\section{Procurement of Reading Materials}

Some of the respondents ( 8 out of 23 ) provide, and are of the view that parents should provide, reading materials and other learning aids for their children. One representative statement, made with a certain degree of pride, reads:

- I am doing a lot for my five year old child by buying her books and other learning aids $\ldots$

The respondents indicated that they buy their children books, magazines and newspapers that are self-teaching, interesting, colourful, and of a wide variety. Other materials that parents procure for their children are (quiz) games that improve their general knowledge. In line with the view that parents conflate reading and learning, they also help their children prepare reading timetables at home. The time-tables are general in nature and thus relate to the reading of educational and leisure materials.

\section{Attending Good Schools}

Some parents (3 out of 23) believe that in order to make sure that they help their children to learn to read and be properly educated, it is necessary to send them to good schools (the so-called 
English medium private schools in Botswana). The consequence, as one of parents phrases it, is that he will then have to:

- Struggle to make ends meet after paying exorbitant school fees in private schools.

There is no doubt that private schools are better equipped than government-aided schools, and that the products of such schools have generally always outperformed students from the public schools. Every parent who can, therefore, sends their children to such schools. This means that it is necessary to make public schools in Botswana compete favorably with private schools in terms of the facilities in them and in terms of other features that make them attractive to parents.

\section{Conclusion}

The main aim of this paper was to present the voices of those, especially at the lower end of the socio-economic ladder, who are never consulted on literacy issues in Botswana. However, it is now clear that this objective was not fully attained for two reasons. First, the data collected was very small; an increase in data size would have made the findings of this study more acceptable. And second, the study presented the views of a cross section people with diverse economic backgrounds. The original intention was to present only the views of those at the lower end of the economic ladder. This shows the difficulty in separating the diverse groups that populate flea markets. In spite of these limitations, it is clear that the voices that have been presented are important and should be listened to.

The respondents raised a lot of issues regarding literacy in Botswana. These include children's lack of interest/motivation in reading, inadequate parental and teacher involvement in reading, poverty and unemployment which account for the lack of awareness about literacy, inadequate libraries and shortage of reading materials, the negative and/or positive influence of technology on reading and lack of community education on the importance of reading. Some parents actually indicated the ways in which they help their children to read and acquire education/literacy. These include teaching their children to read, procuring a variety of colorful and interesting materials for them and making financial sacrifices to send their children to the best schools in the land.

In conclusion, this study has shown the need to adopt a bottom-up approach to complement the traditional top-down approach that has always been used in matters related to literacy in Botswana. This would enable the government and other stakeholders to canvass a wide range of divergent views that would lead to the improvement of the literacy climate of Botswana.

\section{Acknowledgement}

This paper is one of the outcomes of a project supported by the International Reading Association's 2010 grant for countries with developing economies.

\section{References}

Arua, A. E. (2011). Using flea markets as literacy support centers in Botswana. Project report submitted to the International Reading Association, Newark, Delaware.

Arua, A. E., \& Arua, C. E. (2011). The reading behaviour of junior secondary students during school holidays in Botswana. Journal of Adolescent and Adult Literacy 54(8), 589-599.

Arua, A. E., Moanakwena, P. G., Rogers, T., Tierney, R. J., \& Lenters, K. (2005). Improving the quality of learning in the content areas: Situational analysis of secondary level education in Botswana. Paris: UNESCO.

Arua, C. E. (2014). Leisure reading among students in selected community junior secondary schools in Botswana. Unpublished doctoral thesis, University of Botswana, Gaborone. 
Baputaki, C. (2006). Youths promote reading culture. Mmegi, 23(144).

Brown, D., Epners, I., \& Gauvin, A.M. (n.d.). Education and enlightenment: Literacy Awareness Kit. Retrieved September 26, 2009 from: http://www.centreforliteracy.qc.ca/Resources/catalog/fulltext/eduenl/EduEnl.pdf

Chivivi, O. O., Moyo, P., \& Mapuwei, N. (2014). Advertising strategies and tactics applied by the flea market traders to alleviate poverty in Zimbabwe. Case of Mupedzanhamo (Harare) and Global Flea Market (Gweru). European Journal of Business and Management, 6(27). Retrieved from: http://iiste.org/Journals/index.php/EJBM/article/view/15542

Commeyras, M., \& Mazile, B. M. (2011). Exploring the culture of reading among primary school teachers in Botswana. The Reading Teacher, 64(6), 418-428.

Hanemann, U. (2005). Literacy in Botswana. Retrieved October 5, 2014 from: http://portal.unesco.org/education/en/files/43531/11315372211Hanemann U Botswana.doc/Hanema...

Hosia, T. (2007). How far is Botswana in developing a culture of reading? Mmegi, 23, 24.

International Reading Association. (2008). Reading, writing, and technology. Newark, Delaware: International Reading Association

Jongman, N. D. B. (1999). Marang Community Junior Secondary School library. Diploma Project, University of Botswana, Gaborone.

Kamberelis, G., \& Albert, M. K. (2007). Douglas Waples (1893-1978): Crafting the well-read public. In S. E. Israel, \& E. J. Monaghan (Eds), Shaping the reading field: The impact of early reading pioneers, scientific research, and progressive ideas (pp. 247-278). Newark, DE: International Reading Association.

Maisel, R. (1974). The flea market as an action scene. Journal of Contemporary Ethnography 2, 488505.

Mathangwane, J. T., \& Arua, A. E. (2006). Family literacy: Attitudes of parents towards reading in rural communities in Botswana. The Reading Matrix: An International Online Journal, 6(2), 46-59. [http://www.readingmatrix.com/articles/mathangwane_arua/article.pdf]

McEnally, M. R. (1998). An exploratory analysis of flea market shoppers. Retrieved October 30, 2011 from: http://www.sbaer.uca.edu/research/1998/SMA/98sma143.txt

Ntlamelang, B. (1982). Problems and prospect of publishing in Botswana: An investigation of the National Book Development Council of Botswana. Diploma Project, University of Botswana, Gaborone.

Olaofe, I. A. (2003). Building a reading culture in communities where adverse situations thrive. In A.E. Arua, J. Umolu, T. Oyetunde, \& C. E. Onukaogu (Eds.), Reading for all in Africa: Building Communities where Literacy Thrives (pp. 96-100). Newark, DE: International Reading Association.

Oyegoke, L. (2012). Nigeria LNG prize: Great literature or failed criticism. Oye: Ogun Journal of Arts, 18, 38-49.

Parker, A. (2011, May 13). The flea marketing of New York. The New York Times. Retrieved 13 June 2011 from: http://www.nytimes.com/.../nyregion/the-flea-marketing-of-new-york-city.html

Seboni, B., \& Swartland, J. (2009). How government can support writers. Mmegi, 26(137).

Sherry Jr., J. F. (1990). A sociocultural analysis of a Midwestern American flea market. Journal of Consumer Research, 17(1), 13-30.

Tamukamoyo, H. (2009). Survival in a collapsing economy: A case study of informal trading at a Zimbabwean flea market. Doctoral thesis. Retrieved September 26, 2009 from: http://hdl.handle.net/10539/8166

Waite, M. (2007). Oxford dictionary and thesaurus (2 ${ }^{\text {nd }}$ Edition). Oxford: Oxford University Press. 


\section{Appendix}

\section{Questionnaire on Literacy in Botswana}

This questionnaire/interview guide is used to survey the views of parents and other stakeholders in Botswana's march towards Education for All. Your name is not required, and the views you express cannot be traced back to you. Please feel free to respond as frankly as you can.

Thank you.

(Author)

A. Background information

1. Qualifications:

2. Position(s) of respondent(s):

3. Numbers of years in current position:

4. Gender: Male Memale

B. Reading/Literacy Issues in Botswana

1. What do you consider the main reading/literacy issue in Botswana? Please describe the issue. What effort is being made to resolve it?

2. What other reading/literacy issues do you consider important. Please arrange in order of importance:

3. What do you do as a parent to aid the family in teaching literacy?

4. What do you do in terms of teaching your children to read?

5. How has technology impacted literacy use and literacy instruction in your home? Please cite specific ways in which technology has supported or hindered literacy.

6. What role does the community play in promoting reading/literacy in the country?

7. What literacy organizations are present in Botswana? Please describe what these organizations do to support or promote literacy.

\section{Literacy Instruction}


8. Compared to other subjects, approximately how much time is spent on literacy instruction in schools? Please discuss the time spent on literacy from primary grades all the way to high school.

9. What are some of the struggles that students have with literacy in Botswana? How are these students supported?

\section{General}

10. Is there anything important for us to know about Botswana's literacy practices? Please tell us about them. 